\title{
Crash model based on integrated design consistency with low traffic volumes (due to health disaster (COVID-19)/movement control order)
}

\author{
Joewono Prasetijo ${ }^{1}$ (1) - Guohui Zhang ${ }^{2}$. Zulhaidi Mohd Jawi ${ }^{3} \cdot$ Mohd Eizzuddin Mahyeddin $^{1}$. \\ Zaffan Farhana Zainal ${ }^{4} \cdot$ Muhammad Isradi $^{4} \cdot$ Narain Muthukrishnan $^{5}$
}

Received: 20 August 2020 / Accepted: 3 October 2020 / Published online: 20 October 2020

(c) Springer Nature Switzerland AG 2020

\begin{abstract}
Malaysia is listed as one of Asia's developing countries with high-road accidents rate. The accident involves the most between the motorcyclist and other vehicles such as a passenger car which is 17 times safer than the motorcyclist. Current research reveals that the three major forms of incidents in Malaysia are single-motorcycle incidents, passenger car crashes and carsmotorcycles crash. In general, the lack of accuracy of road geometric design, traffic volumes and overlapping movements of vehicles was the main cause of road accidents in Malaysia, which caused drivers to make mistakes and errors due to road geometric characteristics and traffic environments. However, during our recent COVID-19 pandemic, the traffic volumes are relatively low in the whole country as the government announces the movement control order in March 2020. The country was almost completely lockdown (people and vehicles' movements were controlled). In contrast with the reduction of the traffic volumes, the number of crashes shows relatively high numbers. This phenomenon can be derived so that other factors cause vehicle crashes and fatalities should be considered. Several factors related to road geometric such as lane width, shoulder width, access point, curve length and tangent length are considered in developing profiles of operating speed for motorcycles and cars formed of tangents and curves. The analysis of the geometric factors and traffic environments took place at federal road F0050 from 21 to $25 \mathrm{~km}$ in Johor, Malaysia. This study was carried out using GPS (DG-200) where the data (vehicles tracked movements) on the continuous speed profiles used a current method of analysis to determine the profiles of road design consistency for motorcycles and cars. The profiles are used to measure the importance index of the integrated design consistency model of the road. The model depends on parameters such as the confine region of speed profiles, average speed, and velocity deviation standard of the profiles. Therefore, a special software of ACAD was used to build the profile of the consistency model. The design accuracy of the speed profile in traffic and safety assessments are affected by the integrated-consistency model. The highest number of accidents has been identified at $24 \mathrm{~km}$ at F0050 based on the area design consistency where poor design is the integrated quality consistency model for car and motorcycle. The study shows that crashes and fatalities are not fully affected by traffic volumes but road design performances and driving behaviors.
\end{abstract}

Keywords Road accidents $\cdot$ Cars-motorcycles $\cdot$ Movement control order $\cdot$ Geometric features $\cdot$ Linear profiles

\section{Introduction}

According to the World Health Organization (WHO), one million people are killed each year, three million people are seriously injured for life and thirty million are injured in road accidents. Road accident is expected to be the third significant adding to the global burden of disease and injury in 2020. Furthermore, road accidents in Malaysia are one of the

Joewono Prasetijo

joewono@edu.uthm.my

Extended author information available on the last page of the article formidable problems when addressing this country's road traffic. Malaysia is also one of the Asia's developing countries suffering from high road accidents which are around 30,000 accidents recorded and for every year $1 \%$ of its fatal accidents. Vehicle crashes in Malaysia have risen over the last 30 years with a mean incidence of about $9.7 \%$ once a year, consistent with data from the Royal Malaysia Police (PDRM). The vast amount of traffic on the road will lead to collisions involving various types of vehicles [1], the most probable collision between motorcyclists and vehicles. A motorcyclist is 17 times more at risk than a passenger driver; therefore, the driver will be more at risk of injury or death 
because the chance of injury is greater than that of a passenger car. In addition, the probability of injury during an accident is estimated to be 12 times greater than that of a passenger vehicle [15]. Research shows that three major types of accidents are passenger vehicle collisions, other vehicle crashes and single-motorcycle injuries in Malaysia. Several cases of cars and motorcycles accidents, most of the injured were passengers, not drivers or motorcyclists where $97 \%$ of motorcyclists were killed or injured compared to $50.5 \%$ of the drivers. Moreover, $95.4 \%$ of motorcyclists were involved in high-speed motorcycles (single vehicle accidents), and $0.9 \%$ are likely to be injured and collieded with cars [5].

Some reports confirmed that most road accidents occur because of driver fault and mechanical failures such as breakdown and split of the tire. Yet, due to the road conditions, the high number of road accidents occur [1]. The road accident factor continues to increase in Malaysia due to the lack of geometric road design accuracy where drivers make mistakes on lane geometric features. There is a lack of continuity when driving along the geometric features of the road, which will increase the chance of accident $[3,6]$.

\section{5th percentile of operating speed model}

Several models were developed over the past 50 years to estimate the operating speed of vehicles based on traffic flow and geometric characteristics [2]. Several studies have been done by using several types of tools to measure the 85th percentile of speed at the two-lane rural roads along the horizontal curves and tangents, which were based on speed limits and types of vehicles. Most of the models produced are supported spot speed data obtained at the actual locations; therefore, the speed calculation used may be a radar gun that can provide less accuracy because the angle of reading is different from zero and drivers can drive (reduce the speed) inconsistently.

The study was carried out in some studies, which calculated the operating velocity profile from the circular curve radius, the angles of deflection and the relation of curve length. Previous research works have considered only passenger vehicles operating under free-flow conditions, while many previous studies specified curve radius because of the impact parameter on the estimation of operating speeds [8]. In addition, some studies have established operating speed prediction models by supporting continuous operating speed information collected through VBox.

\section{Design consistency model}

The consistency of design is calculated by estimating the variance of speed along successive geometric elements and assessing the deviation of speed from the standard velocity in a geometric feature section of the lane. This could cause drivers to make errors in speed that result in an increased risk of collision [7]. A road with the best quality level will influence the driving force in a safe and careful way to drive, while high speed can be affected by low consistency along a specific path between different drivers and accidents will end [13]. The features of cars, drivers and traffic affect the geometric designs. The volume and width of lanes, the existence and width of shoulders and highway medians are elements of geometric design that affect traffic operations. Therefore, the horizontal and vertical alignment of the movement of vehicles' highways and conflict streams could lead to accidents [14]. The main criteria used to evaluate design consistency are referred to as the 85th percentile vehicle speed evaluation of operating speed, and are obtained through the utilization of predictive models of operating speed. Researchers have expanded in defining the use of continuous speed profiles (area of normalized bounded by altitude). The area is used to assess the variance of vehicle speed along the road sections which are used to determine the profile design consistency for the whole road sections [4, 7, 9]. Methods of consistency assessment are developed by estimating the operating speed profile utilized in other countries such as the United States, Switzerland and Germany. In addition to the previous consistency approach [7], the following new approaches take into account the consistency of road design. The proposed model represents the parameters as the bounded area between the profiles that are based on the average speed along a two-lane highway segment. It can be seen while the consistency of the design increases, the crash rates will show a significant decrease. The equations correspond with a function of $R_{\mathrm{a}}(1)$

$R_{\mathrm{a}}=\frac{\left(\sum a_{i}\right)}{L}$

$R_{\mathrm{a}}$ is the relative area in $\mathrm{m} / \mathrm{s}$ measuring consistency, $\sum a_{i}$ is the total of $i$ bounded area between profiles of speed and operating speed $\left(\mathrm{m}^{2} / \mathrm{s}\right), L$ is the segment length $(\mathrm{m})$ in total

$\sigma=\left\{\frac{\left(V_{j}-V_{\text {avg }}\right.}{n}\right\}^{0.5}$

where $\sigma$ is the standard deviation of vehicle operating speeds $(\mathrm{km} / \mathrm{h}), V_{j}$ is the operating speed of the $j$ th geometric element in tangent/curve $(\mathrm{km} / \mathrm{h}), V_{\text {avg }}$ is the length average weighted of operating speed at a segment $(\mathrm{km} / \mathrm{h}), n$ is the geometric elements along a road segment $(\mathrm{km} / \mathrm{h})$

$V_{\text {avg }}=\frac{\sum V_{i} L_{i}}{\sum L_{i}}$

where $V_{\text {avg }} \quad V_{i}$ is the operating speed $(\mathrm{km} / \mathrm{h})$, and $L_{i}$ is the length of the segment $(\mathrm{km})$. 
The model of consistency (C) and the model integrated design consistency are as follows

$C=2.808 . \exp ^{\left(-0.278 \cdot R_{\mathrm{a}} \cdot \sigma\right)}$

$C$ is the basic consistency of a road segment, $R_{\mathrm{a}}$ is the normalized bounded area based on the average speed profile of cars-motorcycles and the average operating speed $(\mathrm{m} / \mathrm{s})$, $\sigma$ is the standard deviation of car speeds $(\mathrm{m} / \mathrm{s})$.

$\mathrm{IC}=\left[2.808 * \exp ^{\left(-0.278 * R_{\mathrm{a}} * \sigma\right)}\right] * \exp ^{\left(-0.01 * A_{\mathrm{CT}}\right)}$

where IC is the integrated consistency of road sections, $\sigma$ is the standard deviation of car speeds and motorcycles, and ACT is the normalized bounded area between the speed profile of cars and motorcycles $(\mathrm{m} / \mathrm{s})$.

\section{Data collection}

The objective of this research is determining and deriving the performance level of road safety based on the development of linear speed profiles of cars-motorcycles. Based on vehicle size, location, vehicle data velocity using the Global Positioning System (GPS) and road geometric characteristics, the data collection was calculated. The study was conducted on the Johor Federal Road (F0050) from 21 to $25 \mathrm{~km}$ at Batu Pahat Community Nurses College in Taman Manis, Parit Raja, Johor as shown in Fig. 1.

During the daytime, the primary speed data collection was carried out under free flow and off peak, along the selected segment with the GPS DG-200 for vehicle tracking movements. GPS was activated for moving vehicles: cars and motorcycles during which the two vehicles were used (two cars, two motorcycles). A hundred (100) test drivers and riders were instructed to use the same standards for vehicles as drivers and riders driving along the sections selected. In order to avoid the effect of vehicle speed shifts and free flow velocity reduction, speed data from the signalized intersection were omitted at approximately $300 \mathrm{~m}$ space distance [16]. The GPS system has been designed to identify the vehicle locations and speeds at intervals of time in $1 \mathrm{~s}$. The data collected required two surveyors, drivers and GPS trackers. For each segment/road section, the average vehicle travel speeds along the traveled space are determined by GPS [10-12]. In addition, a replacement method was used to generate the continuous speed profile information. Therefore, the index of integrated road design consistency (IC) can be determined based on the speed profiles of cars-motorcycles.

There are secondary sets that provide data from the incident report, traffic volumes and traffic characteristics. Data collection of accident data from the police (PDRM) was obtained, which involves the type of accident, location and number of vehicles involved. Average annual daily traffic (AADT) collected from agencies such as the Highway Design Unit (HPU) is included in the collection of traffic data. Road characteristics include features of the road and direction, such as curve length, tangent length, lane width, shoulder width and entry point. In order to determine the accuracy of the road design model, information was obtained from authorities such as Public Ministry Works (JKR) or by visiting the locations [7].

\section{Result and discussions}

\section{Model of tangent and curve 85th percentile based on operating speed}

Operating speed models are developed based on the current method of analyzing the vehicles' speed profiles. The GPS model of DG-200 was used to collect the speed-time data which are used to plot the profiles. Furthermore, vehicles'

Fig. 1 Location 21-25 km (F0050)

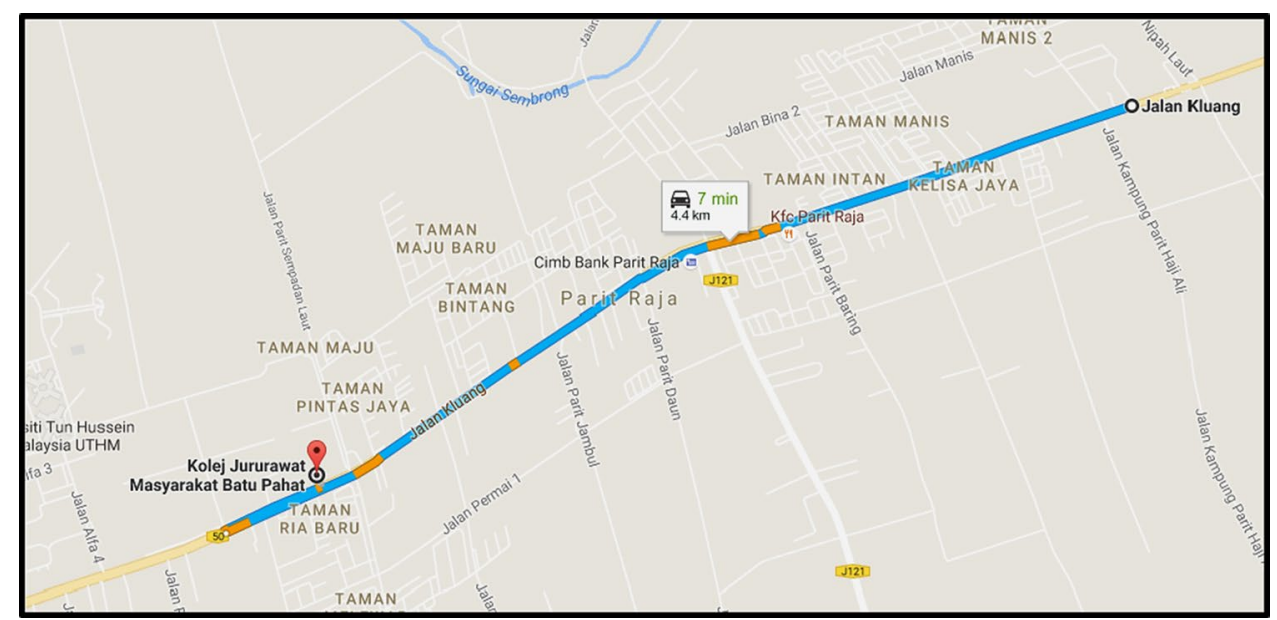


speed and road features were obtained (on site) to produce the 85th percentile of speed. The multiple linear regression approach is used to use the statistical software (Minitab) to construct the 85th percentile speed prediction model. The tangent and curve sections were also considered to estimate the operating speed model for motorcycles and cars. The equation is developed using different variables: length of tangent, curve length, shoulder width, lane width and point of access. The subsequent model shows that the amount of vehicles/volumes of traffic (AADT) did not contribute to the V85 speed. The statistical findings show typical linear functions.

Motorcycles-85th percentile models:

$V_{85 t}=72.0+6.99 \mathrm{SW}+11.7+0.276 \mathrm{AP}-2.61 \mathrm{LW} \quad R^{2}=0.98$

$V_{85 c}=20.6+4.16 \mathrm{SW}+102+0.82 \mathrm{AP} \quad R^{2}=0.79$

Cars-85th percentile models:

$V_{85 t}=88.9+27.4 \mathrm{SW}-1.26+1.07 \mathrm{AP}-16.9 \mathrm{LW} \quad R^{2}=0.99$

$V_{85 c}=-31.1+4.1 \mathrm{SW} 202+1.38 \mathrm{AP} \quad R^{2}=0.83$

$V_{85 t}$ is the tangent speed (operating speed), $V_{85 c}$ is the curve speed (operating speed), $L_{\mathrm{t}}$ is the tangent section (length), $L_{\mathrm{c}}=$ curve sections (length), $\mathrm{SW}=$ shoulder width, $\mathrm{LW}=$ lane width, and $\mathrm{AP}=$ road access point.

\section{Validation of linear profile models}

Validation of the models developed is performed to validate the models' prediction and accuracy. The data of speed observed and the operating speed model were plotted which results in well compared between data and the model. Equations (6) and (8) show the negative (-) effects of the LW to the vehicles' speed behaviors. This could be explained as the typical road geometric features F0050 road with high activities along the edge of a major road. Vehicles tend to slow down and reduce the speed while driving at the wider major road with roadside activities such as shops and illegal

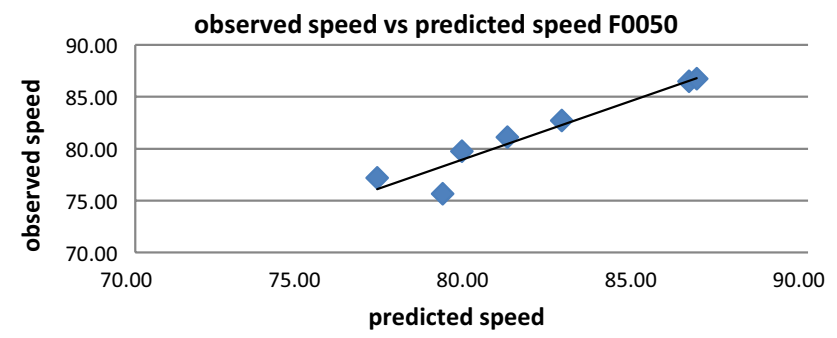

Fig. 2 Comparison observed speed versus predicted speed of motorcycles $(21-25 \mathrm{~km})$ parking. However, the study has found that AP would contribute for the higher speed (+). This is true that vehicles did not reduce the speed while driving at the major road F0050 even though several access points/minor roads are found along the side of the major road. Therefore, Eqs. (6-9) show a high number of $R^{2}$ which means of high and homogenous data and correlation among the variables; V85, L, SW, LW and AP. The figures of the linear line fit to show well compared of observed and predicted linear speed model, which are shown in Figs. 2 and 3. Comparisons of observed velocity versus predicted motorcycle speed at $21-25 \mathrm{~km}$ are shown in Fig. 2, and comparisons of observed velocity versus predicted car speed at $21-25 \mathrm{~km}$ are shown in Fig. 3.

\section{Development design consistency}

The consistency of the design is verified by using the models of continuous speed profile operations. ACAD software was used to develop a road design consistency model. Plots of the model operating speed profile (85th percentile) along the length are called as speed profiles and are used in this study. The graph line represents the early-developed models of the operating speed along the $j$ th geometric elements that represented tangent and curve of roads. The motorcycle speed profile of F0050 21-25 km is shown in Fig. 4, and the car speed profile of $21-25 \mathrm{~km}$ is shown in Fig. 5. Using the 85th percentile of the operating

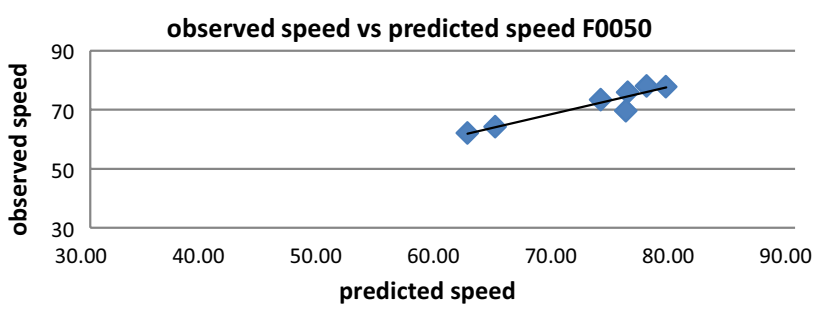

Fig. 3 Comparison observed speed vs. predicted speed of cars (21$25 \mathrm{~km})$

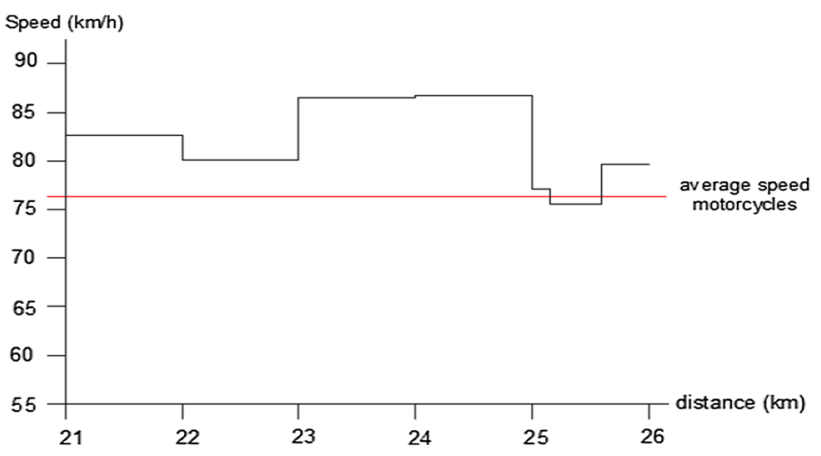

Fig. 4 Speed profile F0050 of motorcycles (21-25 km) 


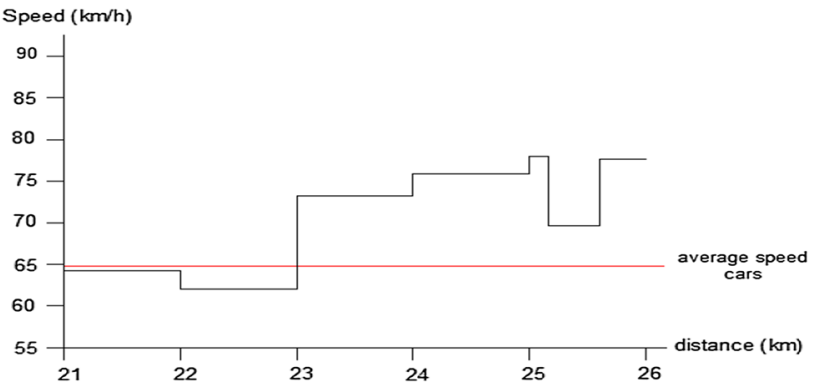

Fig. 5 Speed profile F0050 of cars (21-25 km)

Table 1 Design consistency

\begin{tabular}{lll}
\hline Km & $\begin{array}{l}\text { Design } \\
\text { consistency }\end{array}$ & Threshold \\
\hline 21 & 1.02 & Acceptable \\
22 & 1.55 & Acceptable \\
23 & 0.55 & Poor \\
24 & 0.53 & Poor \\
25 & 2.10 & Good \\
\hline
\end{tabular}

Table 2 Design consistency cars $(21-25 \mathrm{~km})$ per $\mathrm{km}$ motorcycles $(21-25 \mathrm{~km})$ per $\mathrm{km}$

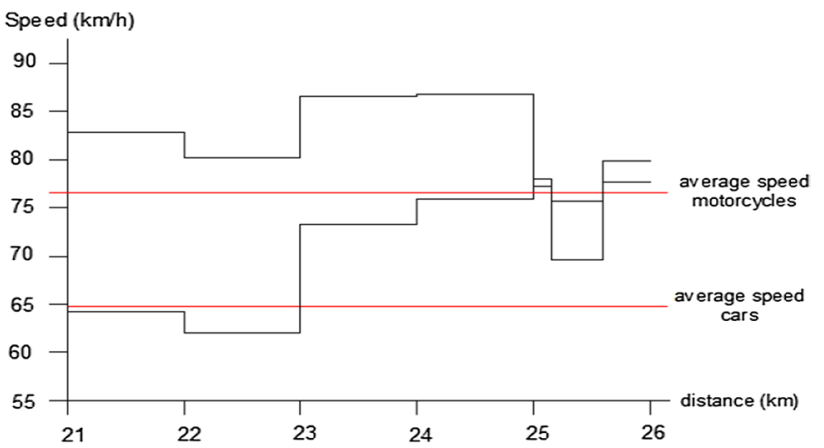

Fig. 6 Speed profile F0050 of motorcycles and cars (21-25km)

Table 3 Integrated design consistency motorcycle and cars (21$25 \mathrm{~km})$ per km

\begin{tabular}{llll}
\hline $\mathrm{Km}$ & $\begin{array}{l}\text { Integrated design con- } \\
\text { sistency }\end{array}$ & Threshold & APW \\
\hline 21 & 2.08 & Good & 26.0 \\
22 & 1.37 & Acceptable & 11.8 \\
23 & 0.48 & Poor & 12.8 \\
24 & 0.30 & Poor & 72.4 \\
25 & 0.45 & Poor & 51.8 \\
\hline
\end{tabular}

\begin{tabular}{lll}
\hline $\mathrm{km}$ & $\begin{array}{l}\text { Design } \\
\text { consistency }\end{array}$ & Threshold \\
\hline 21 & 2.50 & Good \\
22 & 1.64 & Acceptable \\
23 & 0.55 & Poor \\
24 & 0.33 & Poor \\
25 & 0.46 & Poor \\
\hline
\end{tabular}

speed model, the continuous operating speed profile models were plotted. The linear lines pattern shows the motorcycles-cars speed along the segment of roads that depend on the road environmental factors: traffic signal location, access point and intersection along segments. Furthermore, architectural factors were also considered effects on motorcycle and vehicle speeds: shoulder width, lane width, and median and access point.

The following model is developed based on the speed profiles establishment which relies on two main parameters: speed and road geometric features. The design consistency of every road sections is based on Eqs. (1), (2) and (3). The equations are assessed for every road segment per $\mathrm{km}$. Furthermore, the bounded area between the profiles, the vehicles' average speed and the standard deviation of speeds along a two-lane highway segment was defined. A consistency model was created based on Eq. (4). Table 1 displays motorcycles profile performances at $21-25 \mathrm{~km}$ per $\mathrm{km}$ while cars at $21-25 \mathrm{~km}$ per $\mathrm{km}$ are shown in Table 2 .

\section{Integrated design consistency model}

An integrated-consistency model is required in developing the function of car and motorcycle speed profiles. The model is included with the effect of motorcycles speed profiles on design performances. Figure 6 shows an F0050 speed profile at $21-25 \mathrm{~km}$ between motorcycles and cars. The normalized bounded area between the motorcycles and cars speed profiles is calculated by means of the speed profiles. Table 3 demonstrates an integrated feature consistency at $21-25 \mathrm{~km}$ per $\mathrm{km}$ between motorcycles and cars. Each kilometer road section shows value-integrated consistency in design and their threshold per $\mathrm{km}$. The accuracy of integrated design consistency is evaluated using Eq. (5).

The speed consistency model was developed for every kilometer $(21-25 \mathrm{~km})$. The consistency model along $21 \mathrm{~km}$ of motorcycles design consistency shows an acceptable design and good performances for cars. Motorcycles-cars integrated speed consistency shows good performances along the road sections surrounding areas with mosque, restaurants. Intersections and access points with no median/ divider were found along the sections which result in conflict movements and accidents on the road. The bounded area of speed consistency motorcycles-cars gives an acceptable performance at $22 \mathrm{~km}$ and the integrated consistency cars-motorcycles perform suitable profiles. The study found suitable consistency along the road Ayer Hitam-Batu Pahat 
even though the road does not have a median that can cause vehicle conflicts, which contribute to the accidents.

Results on IC bounded profiles at 23 and $24 \mathrm{~km}$ for cars-motorcycles show poor design consistency while the integrated design consistency also shows poor design for both types of vehicles. This can be concluded based on areas surrounding that the road geometric design considered are not designed properly which is not suitable for traffic flow streams; the roads are located close to several road activities such as shop and illegal parking at road shoulders. Car drivers and motorcyclists commonly drive at the high speed along the federal roads, which can be derived with good performances of integrated speed consistency for cars-motorcycles. However, performances decrease as cars drive through $25 \mathrm{~km}$ with poor consistency same as the integrated design consistency cars-motorcycles. Vehicles tend to drive with higher speed along the section of $25 \mathrm{~km}$, and cars-motorcycles travel with comfort due to straight road section which mostly results in a high accident rate.

\section{Conclusions}

The following study has conducted the analysis of speed design consistency at federal road F0050 in Johor. The following study of the integrated design consistency between the motorcycles and cars along $\mathrm{km} 21$ up to $\mathrm{km} 25$ indicates that poor road design consistency would likely results in more accident occurs. The study found that there are several access points along the section along a road ( $\mathrm{km} 21-\mathrm{km} 25)$ and mostly vehicles coming from minor roads cross the main road without hesitation, which creates the potential of more conflict traffic streams. The conflicts would results in number of accidents on road traffic movements with particularly motorcycles and cars. The un-availability of road dividers (two-way directions) along the roads could be the worst conditions, in which drivers tend to cross the road from a different direction without any control/no separations.

The standard of road design would impress the driving force and behaviors of drivers and motorcyclist to drive along the road safely. Therefore, road geometric design performance level for suitable vehicles-motorcycle movements should be designed with results in sophisticated integrated design consistency between cars-motorcycles where good, fair/reasonable and poor design consistencies are specified as the road performance level.

Acknowledgments The authors' appreciation goes to the Universiti Tun Hussein Onn Malaysia and the Ministry of Higher Education Malaysia for supporting this research through Fundamental Research Grant Scheme (FRGS) Grant Vot. 1452 (Ref: FRGS/1/2014/TK07/
UTHM/02/2). Thanks also goes to the Sustainable Transport and Safety Studies (STSS) Focus Group, Department of Transportation Engineering Technology, Universiti Tun Hussein Onn Malaysia.

\section{Compliance with ethical standards}

Conflict of interest On behalf of all authors, the corresponding author states that there is no conflict of interest.

\section{References}

1. Abdullah L, Zamri N (2012) Road accident models with two threshold levels of fuzzy linear regression. J Emerg Trends Comput Inf Sci 3(2):225-230

2. Castro M, Iglesias L, Rodriguez-Solano R, Sanchez, JA (2008) Highway safety analysis using geographic information systems. In: Proceedings of the Institution of Civil Engineers-transport, vol 161, No. 2. Thomas Telford Ltd., pp 91-97.

3. De Oña J, Garach L (2012) Accidents prediction model based on speed reduction on spanish two-lane rural highways. Procedia Soc Behav Sci 53:1010-1018

4. Gibreel GM, Easa SM, Hassan Y, El-Dimeery IA (1999) State of the art of highway geometric design consistency. J Transp Eng 125(4):305-313

5. Hung D, Stevenson M, Ivers R (2006) Prevalence of helmet use among motorcycle riders in Vietnam. Injury Prev 12:409-413

6. Lamm R, Psarianos B, Mailaender T (1999) Highway design and traffic safety engineering handbook. McGraw Hill, Inc., New York

7. Mattar-Habib C, Polus A, Farah H (2008) Further evaluation of the relationship between enhanced consistency model and safety of two-lane rural roads in Israel and Germany. EJTIR 7:320-332

8. Memon RA, Khaskheli GB, Dahani MA (2012) Estimation of operating speed on two lane two way roads along N-65 (SIBIQuetta). Int J Civ Eng 10(1):25-31

9. Polus A, Mattar-Habib C (2004) New consistency model for rural highways and its relationship to safety. J Transp Eng 130(3):286-293

10. Prasetijo J, Zhang G, Guntor N, Siang A, Daniel B, Sanik M (2018) Change of road integrated design consistency due to antiskid transverse rumble strips on high-speed federal road FT050. ASTM Int Adv Civ Eng Mater 7(3):460-472

11. Prasetijo J, Musa WZ (2016) Modeling zero-inflated regression of road accidents at Johor Federal Road F001. In: MATEC web of conferences, vol. 47, 03001. EDP Sciences

12. Prasetijo J, Zainal ZF (2016) Development of continuous speed profile using GPS at Johor Federal Roads F0050. In: MATEC web of conferences, vol 47. EDP Sciences

13. Prasetijo J, Musa W Z, Zainal WZ (2017) Road fatality model based on over-dispersion data along federal route F0050. In: MATEC web of conferences, vol 103. EDP Sciences.

14. Prasetijo J, Pour MH, Ghadiri SMR (2011) Capacity of unsignalized intersections under mixed traffic conditions. Procedia Soc Behav Sci 16:676-685

15. Radin U (2005) Updates of road safety status in Malaysia. IATSS Res 29:78-80

16. Schurr KS, McCoy PT, Pesti G,Huff R (2002) Relationship of Design, Operating, and Posted Speeds on Horizontal Curves of Rural Two-Lane Highways in Nebraska. Transp Res Rec J Transp Res Board 1796:60-71 


\section{Affiliations}

\section{Joewono Prasetijo ${ }^{1}$ (D) Guohui Zhang ${ }^{2}$. Zulhaidi Mohd Jawi ${ }^{3} \cdot$ Mohd Eizzuddin Mahyeddin $^{1}$.} Zaffan Farhana Zainal ${ }^{4} \cdot$ Muhammad Isradi $^{4} \cdot$ Narain Muthukrishnan $^{5}$

Guohui Zhang

guohui@hawaii.edu

Zulhaidi Mohd Jawi

zulhaidi@miros.gov.my

Mohd Eizzuddin Mahyeddin

eizzuddin@uthm.edu.my

Zaffan Farhana Zainal

zfan_ana@yahoo.com

Muhammad Isradi

isradi@mercubuana.ac.id

Narain Muthukrishnan

naraincr7@yahoo.com
Department of Transportation Engineering Technology, Universiti Tun Hussein Onn Malaysia, 84600 Panchor, Johor, Malaysia

2 Department of Civil and Environmental Engineering, University of Hawai'i at Manoa, 2540 Dole Street, Honolulu, HI 96822, USA

3 Malaysian Institute of Road Safety Research (MIROS), 43000 Kajang, Malaysia

4 Faculty of Engineering Technology, Universiti Tun Hussein Onn Malaysia, 84600 Panchor, Johor, Malaysia

5 Universiti Terbuka Malaysia, 31350 Ipoh, Perak, Malaysia 